\title{
Rancang Bangun Trainer Konverter berbasis Arduino Mega 2560 sebagai Sarana Praktikum di Laboratorium Listrik Politeknik Penerbangan Surabaya
}

\author{
Oleh : \\ Rikza KS \\ Rifdian IS
}

\author{
Politeknik Penerbangan Surabaya \\ Jl. Jemur Andayani I No. 73 Surabaya
}

\begin{abstract}
ABSTRAK
Salah satu mata kuliah Program Studi Diploma III Teknik Listrik Bandar Udara yaitu elektronika daya. Dalam mata kuliah tersebut terdapat materi tentang penyearah tegangan, buck konverter, boost konverter dan inverter yang biasa disebut sebagai konverter daya atau pengkonversian daya dari $a c$ ke $d c, a c$ ke $a c, d c$ ke $d c$ maupun $d c$ ke $a c$ yang sangat berguna sekali bagi manusia untuk memenuhi kebutuhan energi sehari-hari.

Pada pengkonversian daya perlu kita ketahui pula bentuk gelombang dari input dan output dari suatu rangkaian konverter agar dapat kita ketahui perbedaan dari kedua gelombangnya agar tidak salah memilih rangkaian konverter mana yang tepat untuk menyuplai suatu beban. Sehingga tidak merusak komponen-komponen dari rangkaian konverter maupun beban yang akan disuplai.

Pada konverter terdapat berbagai macam komponen - komponen elektronika yang memiliki sifat - sifat dan fungsi tertentu yang terintegrasi untuk menghasilkan konversi yang dibutuhkan. Sehingga pemahaman tentang komponen pada konverter perlu dimiliki dengan kontrol dan monitor bebasis mikrokontroler melalui Personal Computer.

Kata kunci : Penyearah tegangan, Buck dan Boost Konverter, Inverter, Konverter daya, Mikrokontroler

\section{PENDAHULUAN}

Pada laboratorium Listrik terdapat berbagai macam alat peraga kelistrikan di dalamnya, sebagai contoh: Relay, Lampu, Power Supply dan berbagai alat ukur, sehingga taruna dapat melakukan banyak eksperimen, pembelajaran, praktikum, terdapat pula konverter yang digunakan untuk bidang industri maupun rumah tangga. Sebagai contoh yaitu rectifier, inverter dan sebagainya.

Konverter merupakan peralatan listrik yang digunakan untuk mengkonversi power supply untuk dirubah outputannya sesuai peralatan yang akan di suplai, sehingga sangat perlu bagi Taruna DIII Teknik Listrik Bandara mengetahui prinsip kerja maupun berbagai komponen yang ada pada alat tersebut. Dan juga perlu rancangan khusus agar taruna dapat melihat bagian-bagian dari alat mulai dari input sampai output pada konverter yang digunakan dalam laboratoriu muntuk pembelajaran.
\end{abstract}

\section{METODOLOGI PENELITIAN}

Konsep dasar rancangan konverter ini yaitu mengontrol dan memonitor bentuk grafik gelombang arus \& teganganinput dan output trainer konverter menggunakan software labview yang di instal pada personal computer. Untuk itu penyelesaian masalah yang dilakukan oleh penulis dengan membagi setiap bagian kedalam suatu blok diagram sesuai dengan fungsinya masing-masing. Dibawah ini merupakan gambar blok diagram rancang banguntrainer konverter berbasis arduino mega 2560 : 


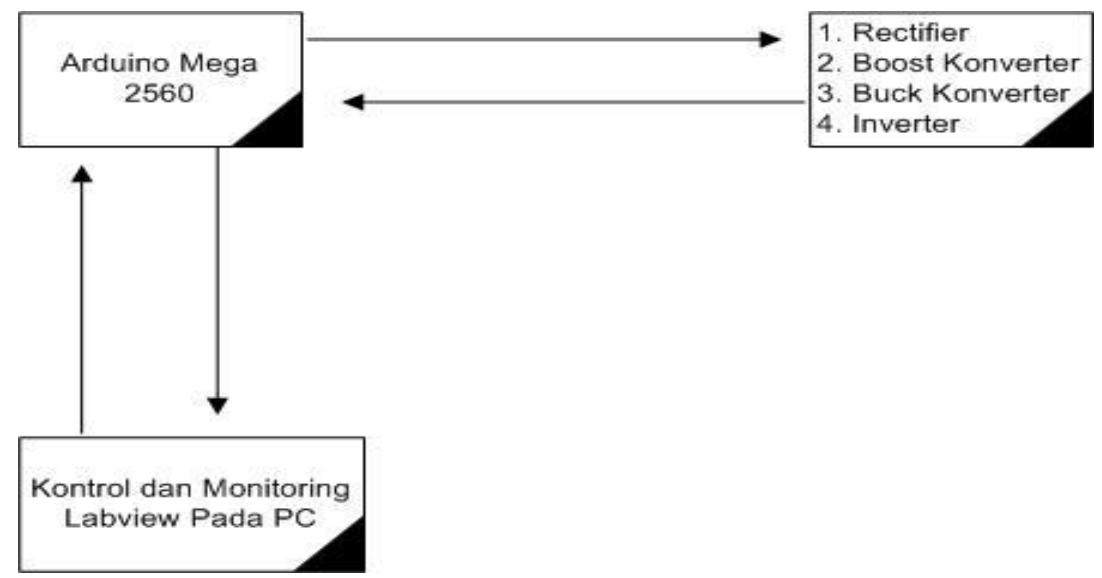

Gambar 1. Blok Diagram Rancang Bangun TrainerKonverter Berbasis Arduino

Berdasarkan gambar 1. penulis akan membuat perencanaan dan pembuatan perangkat pada sebagai berikut :

a. Perencanaan pembuatan rangkaianmonitoringrectifier, boost konverter, buck konverter dan inverter padaprogram software labview

b. Perencanaan pembuatan kontrol untuk trainer dengan program software labview

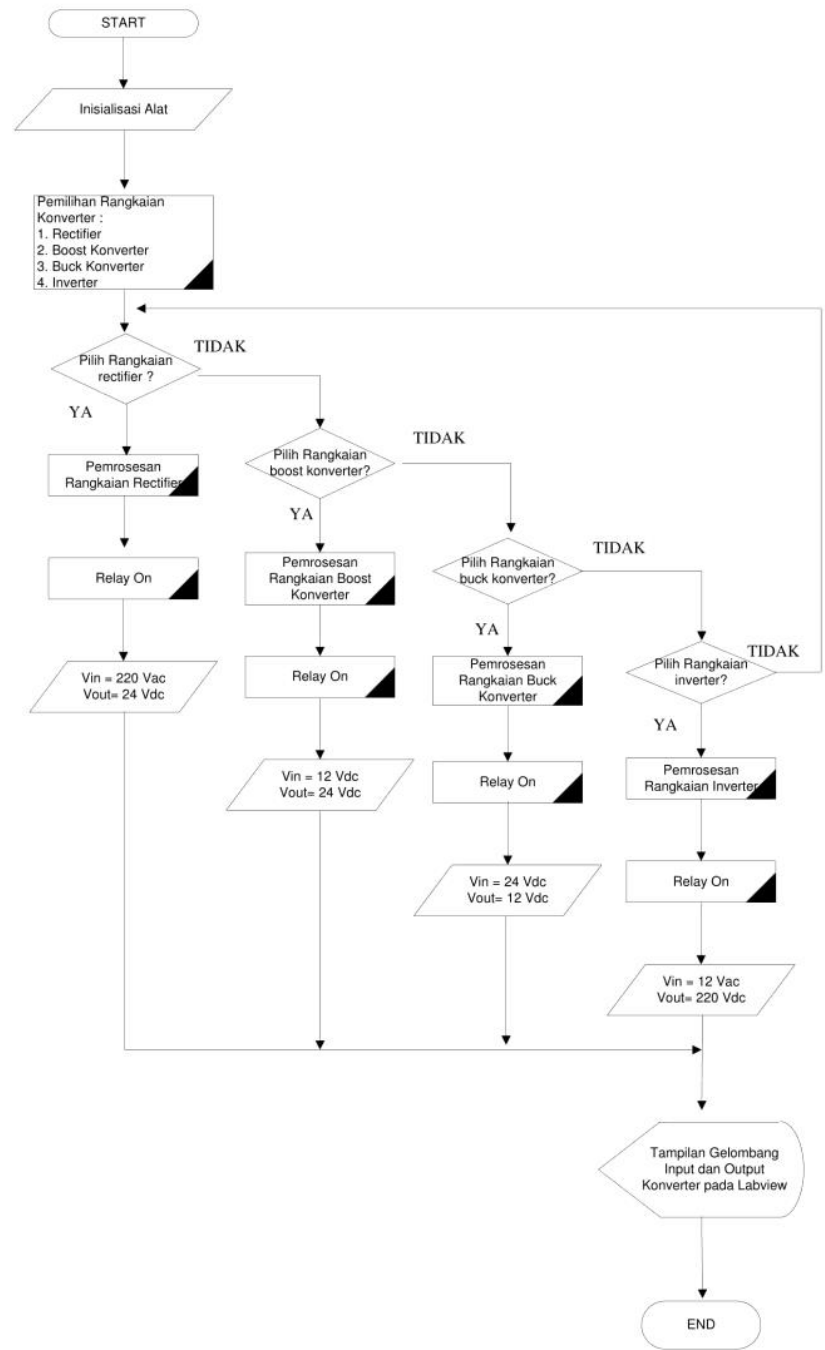

Gambar 2. Flowchart Rancang Bangun Trainer Konverter Berbasis Arduino 
Dari gambar 2 diatas dijelaskan bahwa prinsip kerja dari rancangan ini adalah mengontrol dan memonitor grafik gelombang arus \& tegangan dari konverter yang dipilih oleh user.

Awal mulanya keempat konverter posisi off, kemudian ketika aplikasi labview di operasikan oleh user untuk memilih konverter mana yang ingin dimonitor sesuai dengan program yang sudah dibuat pada Arduino Mega 2560 maka relai konverter yang dikontrol oleh user akan energized dan muncul bentuk grafik arus dan tegangan input dan output pada interface labviewpersonal computer.

\section{Perancangan dan Pembuatan Alat}

\section{Perangkat Keras}

Perencanaan perangkat keras yang akan penulis buat terdiri dari rangkaian buck konverter, rangkaian boost konverter, rangkaian rectifier dan rangkaian inverter yang nantinya akan diberi fuse sebagai proteksi apabila ada gangguan untuk melindungi konverter agar tidak rusak, sensor tegangan untuk membaca tegangan input dan output konverter, sensor arus untuk membaca arus input dan output konverter, serta module relay untuk mengontrol konverter untuk on/off. Dibawah ini adalah skema rancangan yang ingin penulis buat.

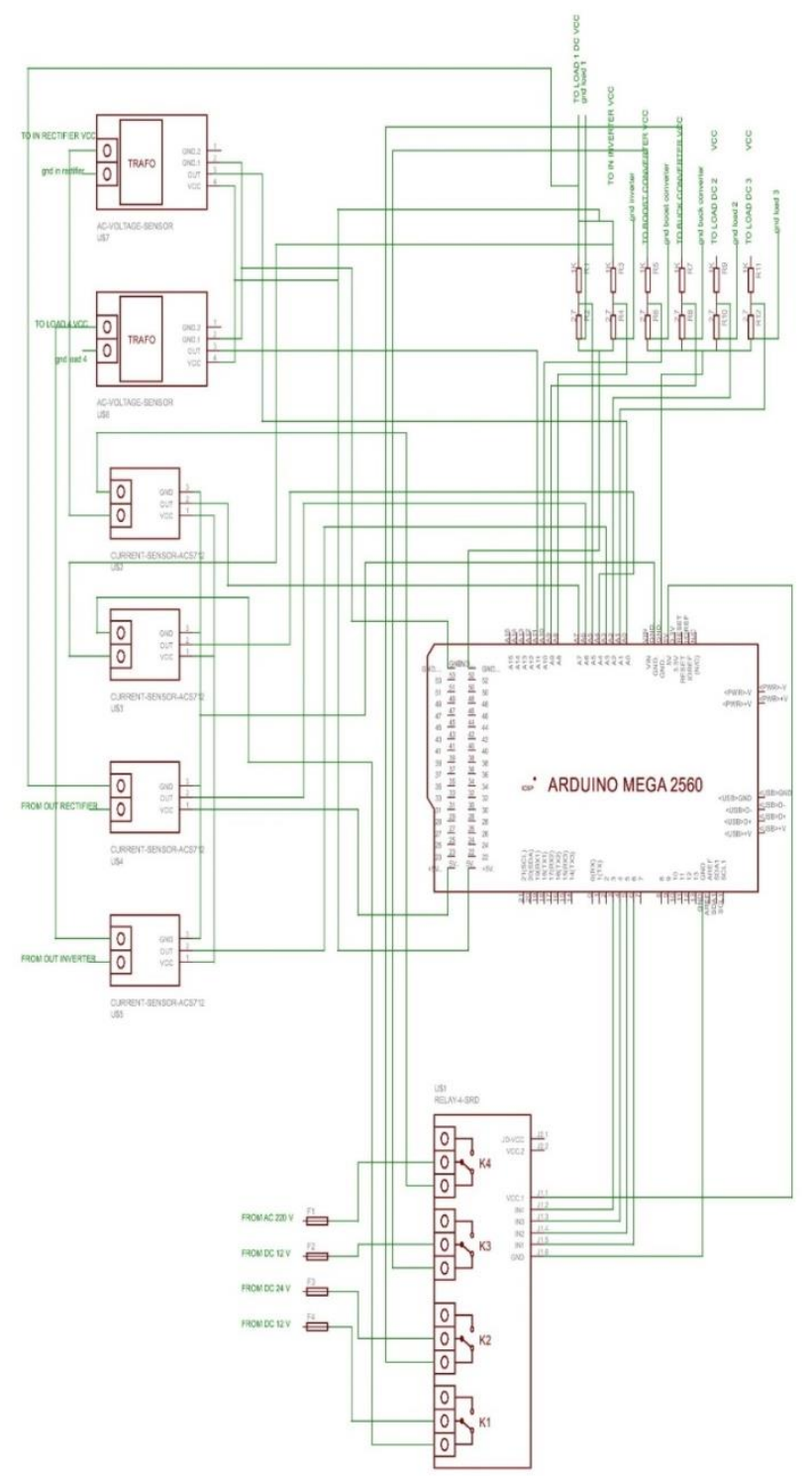

Gambar 3. Skema Rancangan Alat 


\section{Perencanaan Pembuatan Buck Konverter}

Tabel 1. Parameter Pembuatan Rangkaian Buck Konverter

\begin{tabular}{|c|c|c|}
\hline Parameter & Simbol & Nilai \\
\hline Tegangan Masukan & Vin & $24 \mathrm{~V}$ \\
\hline Tegangan Keluaran & Vout & $12 \mathrm{~V}$ \\
\hline Arus Keluaran & Isc & $0.1 \mathrm{~A}$ \\
\hline Ripple Arus & $\Delta \mathrm{I}$ & $5 \%$ \\
\hline Ripple Tegangan & $\Delta \mathrm{V}$ & $5 \%$ \\
\hline Frekuensi & $\mathrm{F}$ & $20 \mathrm{KHz}$ \\
\hline Duty Cycle & $\mathrm{D}$ & 0.5 \\
\hline Nilai Induktor & $\mathrm{L}$ & $0.718 \mathrm{mH}$ \\
\hline Nilai Kapasitor & $\mathrm{C}$ & $1.04 \mu \mathrm{F}$ \\
\hline
\end{tabular}

Rangkaian buck konverterdibangun oleh komponen Mosfet IRFp460, dioda MUR1560, induktor dan kapasitor. Penggunaan mosfet dan dioda ini terdiri dari masing-masing empat buah yang dirangkai secara paralel sehingga didapatkan rangkaian yang memiliki kapasitas hantar arus yang besar. Rumus duty cyclebuck konverter adalah $\mathrm{D}=\mathrm{Vo} / \mathrm{Vin}$.Dengan nilai-nilai dari parameter di atas maka penulis dapat merencanakan pembuatan rangkaian Buck konverter seperti gambar 4 dibawah ini.

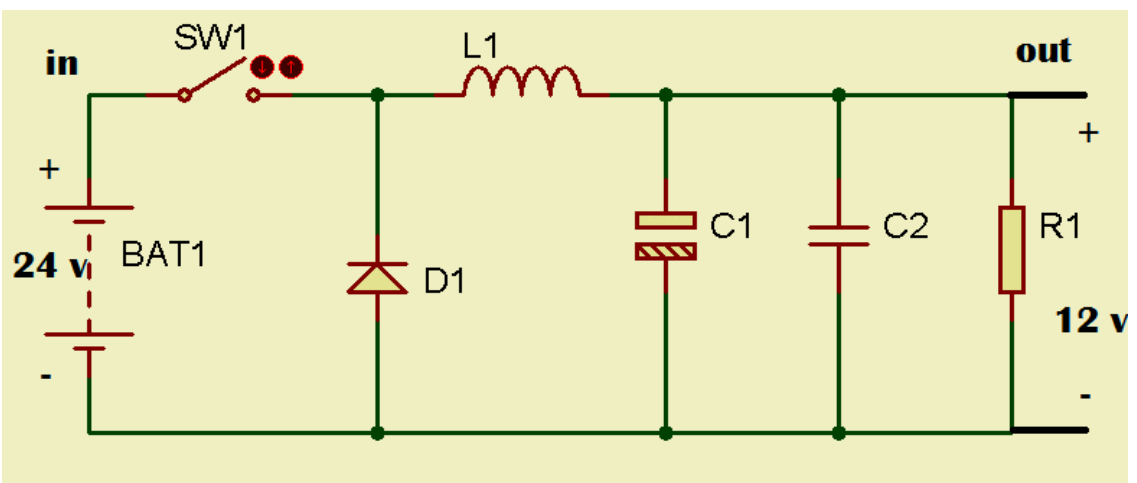

Gambar 4. Rangkaian Buck Konverter

\section{Perencanaan Pembuatan Boost Konverter}

Berikut ini tabel parameter yang harus ditentukan dalam perancangan boost konverter agar dapat menentukan besaran komponen yang digunakan.

Tabel 2. Spesifikasi BoostKonverter

\begin{tabular}{|c|c|c|}
\hline Paramater & Silmbol & Nilai \\
\hline Tegangan Input & Vin & $12 \mathrm{Vdc}$ \\
\hline Tegagan Output & Vo & $24 \mathrm{Vdc}$ \\
\hline Arus Output & Io & $0.12 \mathrm{~A}$ \\
\hline Frekuensi Switching & Fs & $3 \mathrm{KHz}$ \\
\hline Ripple Tegangan & - & $2 \%$ \\
\hline Arus total & $\Delta \mathrm{I}$ & $30 \%$ \\
\hline Duty Cycle & $\mathrm{D}$ & 0.5 \\
\hline
\end{tabular}


Perancangan rangkaian boost konverter akan menghitung besar komponen yang dipakai dan menentukan paramater yang dibutuhkan dalam perancangan boost konverter. Rumus duty cycle dari Boost konverter adalah Vo=Vin/1-D. Gambar 5 merupakan perancangan boost konverter dengan komponen utama MOSFET, dioda, induktor dan kapasitor.

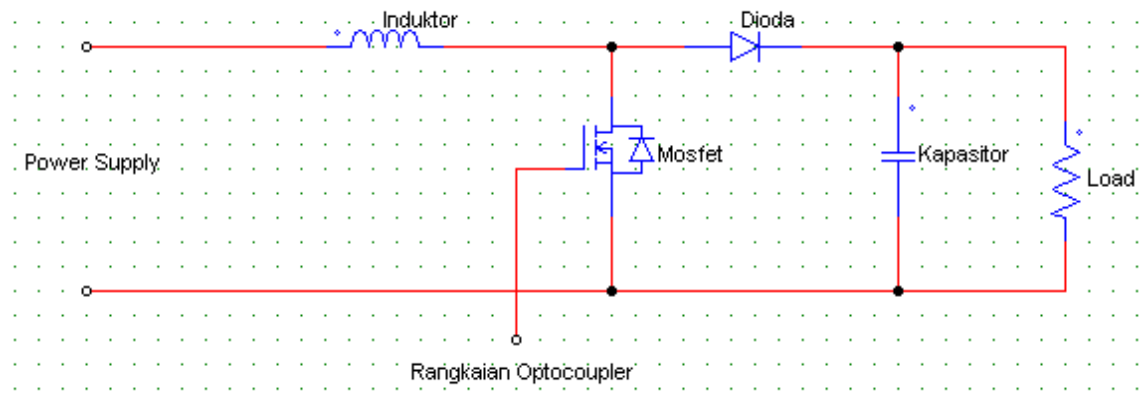

Gambar 5. Rangkaian Rancangan Boost Konverter

Menentukan nilai induktor :

$\mathrm{Vo}=\mathrm{Vin} / 1-\mathrm{k}$

$\mathrm{K}=1-\mathrm{Vin} / \mathrm{Vo}=1-21,6 / 48=0,55$

$\mathrm{IL}=\mathrm{Io} / 1-\mathrm{k}=3 / 1-0,55=6,6 \mathrm{~A}$

$\Delta \mathrm{I}=30 \% \times 6,6=1,99 \mathrm{~A}$

$\Delta \mathrm{I}=\mathrm{Vs}(\mathrm{Vo}-\mathrm{Vs}) / \mathrm{f} \mathrm{L}$ Vo

$\mathrm{L}=\mathrm{Vs}(\mathrm{Vo}-\mathrm{Vs}) / \mathrm{f} \times \Delta \mathrm{I} \times \mathrm{Vo}=21,6(48-21,6) / 3000 \times 1,99 \times 48=1,989 \mathrm{mH}=2 \mathrm{mH}$

Menentukan nilai kapasitor Ripple tegangan : $2 \%$

$\Delta \mathrm{Vc}=2 \% \mathrm{x} 48=0,96$

$\Delta \mathrm{Vc}=$ Io $(\mathrm{Vo}-\mathrm{Vin}) / \mathrm{Vo} \times \mathrm{f} \times \mathrm{C}$

$\mathrm{C}=\mathrm{Io}(\mathrm{Vo}-\mathrm{Vin}) / \mathrm{Vo} \times \mathrm{f} \times \Delta \mathrm{Vc}=3(48-21,6) / 48 \times 3000 \times 0,96=572,9 \mu \mathrm{F}$

\section{Perencanaan PembuatanRectifier}

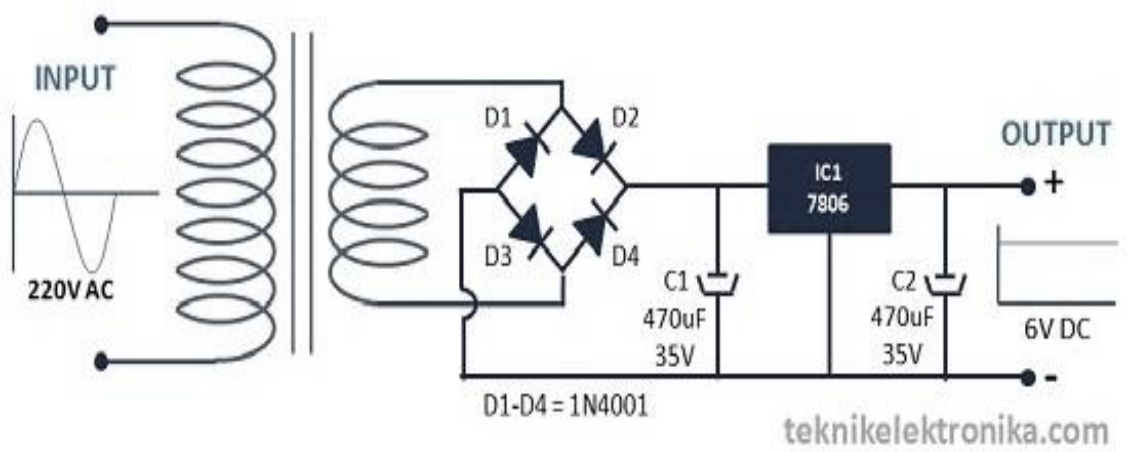

Gambar 6. Rangkaian Rectififer Dengan 4 Dioda

Pembuatan Rectifier ini dibutuhkan bahan-bahan sebagai berikut :

1. Transformer jenis step-down $12 \mathrm{Vdc}$

2. Dioda bridge untuk rectififer

3. Kapacitor elektrolit atau ELCO (Electrolyte Capacitor)

4. Voltage regulator/pengatur tegangan (IC 7806) 
Ketika setengah periode pertama (polaritas + ), dioda D2 dan D3 ON sedangkan dioda D1 dan D4 $O F F$ sehingga arus i1 mengalir melalui D2, RL, dan D3. Selanjutnya, setengah periode kedua (polaritas-), dioda D1 dan D4 ON sedangkan dioda D2 dan D3OFF sehingga arus i2 mengalir melalui D1, RL, dan D4.Dengan demikian, arus yang mengalir ke beban merupakan penjumlahan dari dua arus i1 dan i2. Besarnya arus rata-rata pada beban adalah sama seperti penyearah gelombang penuh dengan trafo $C T$, yaitu : $\mathrm{Idc}=2 \mathrm{Im} / \Delta=0.636 \mathrm{Im}$ dan PIV masing-masing dioda adalah : PIV $=\mathrm{Vm}$.

\section{Perencanaan Pembuatan Inverter}

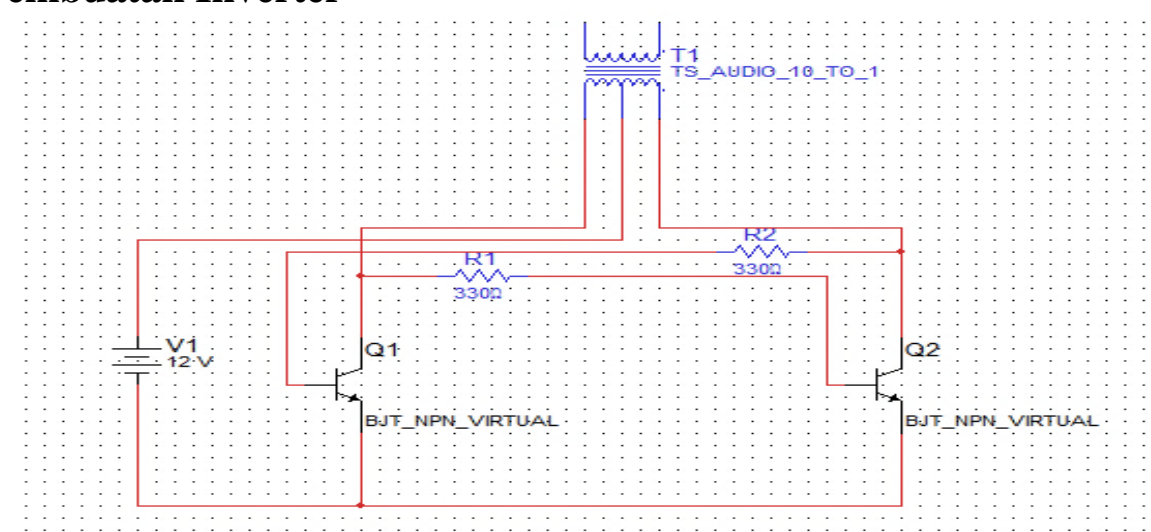

Gambar 7. Rangkaian inverter

Daftar Komponen

a. Transistor Q1,Q2 : 2N3055

b. Resistor R1,R2 : $330 \mathrm{ohm}, 2$ watt

c. Trafo T1 : Trafo step-down, Primer AC $230 \mathrm{~V}$ - Sekunder 12V (CT 12V)

d. Baterai B1 : Aki 12 Vdc

Proses kerja dari rangkaian inverter diatas adalah dari tegangan Baterai $12 \mathrm{Vdc}$ kemudian melewati resistor $330 \mathrm{ohm}$ sebagai driver untuk memicu transistor bekerja yang kemudian 2 transistor 2N3055 membangkitkan tegangan ac $220 \mathrm{~V}$ pada trafo.

\section{Perangkat Lunak}

Perencanaan Pemrogaman Arduino Mega 2560\& Labview

Dalam perencanaan pembuatan program pada Arduino Mega 2560 yang dikomunikasikan dengan labview diperlukan 3 tahapan, yaitu :

\section{a. MenguploadTipe Arduino yang Akan Digunakan}

Tipe arduino yang di pake oleh penulis adalah arduino mega 2560 karena memerlukan lebih banyak port analog input untuk digunakan. Proses uploading arduino cukup mudah yaitu dengan cara memilih menu tool maker hub linx linx firmware wizard. Lalu akan muncul tampilan seperti gambar dibawah ini.

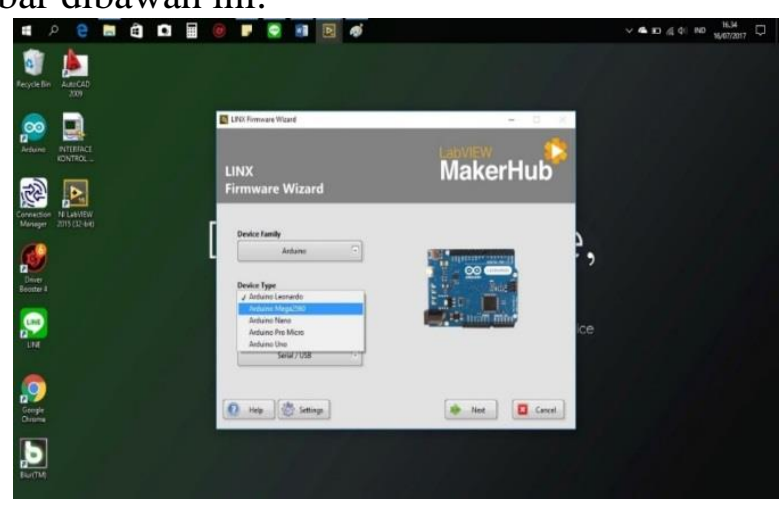

Gambar 8. Pemilihan Tipe Arduino Yang Akan Di Gunakan 


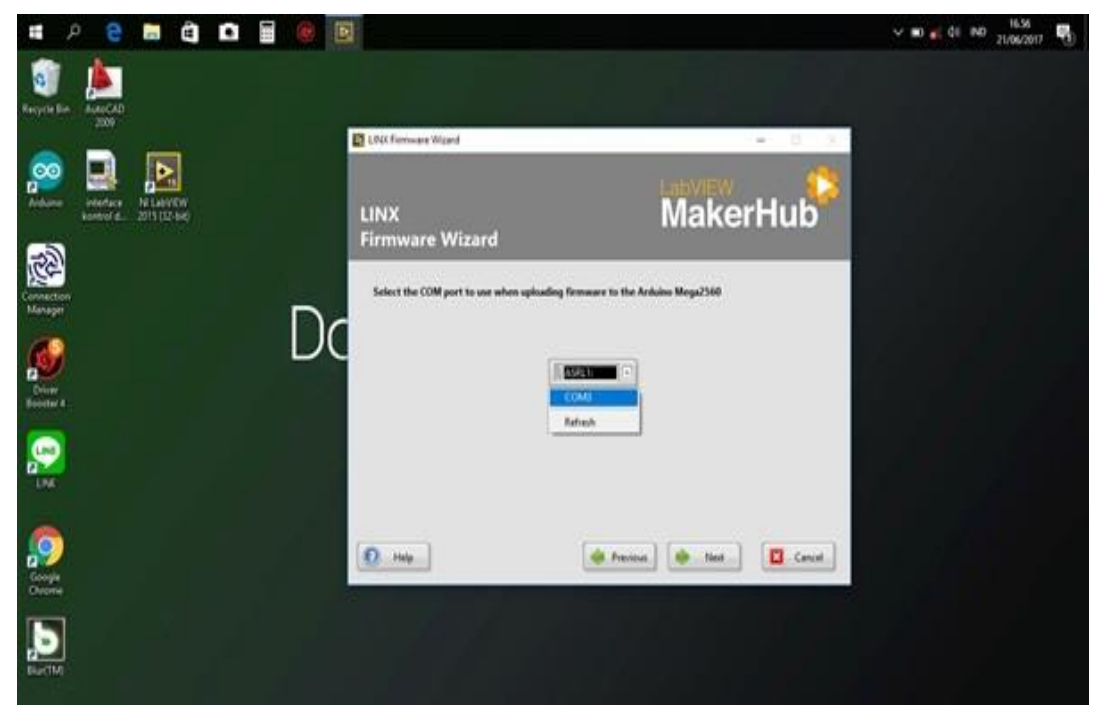

Gambar 9. Pemilihan Com Arduino

\section{b. Membuat Wiring Program pada Block Diagram Labview}

Block Diagram adalah tempat pembuatan program. Jendela tidak akan terlihat oleh pengguna saat program dijalankan. Pembuatan program disini dilakukan dengan cara menempatkan beberapa node dan menghubungkannya satu sama lain.

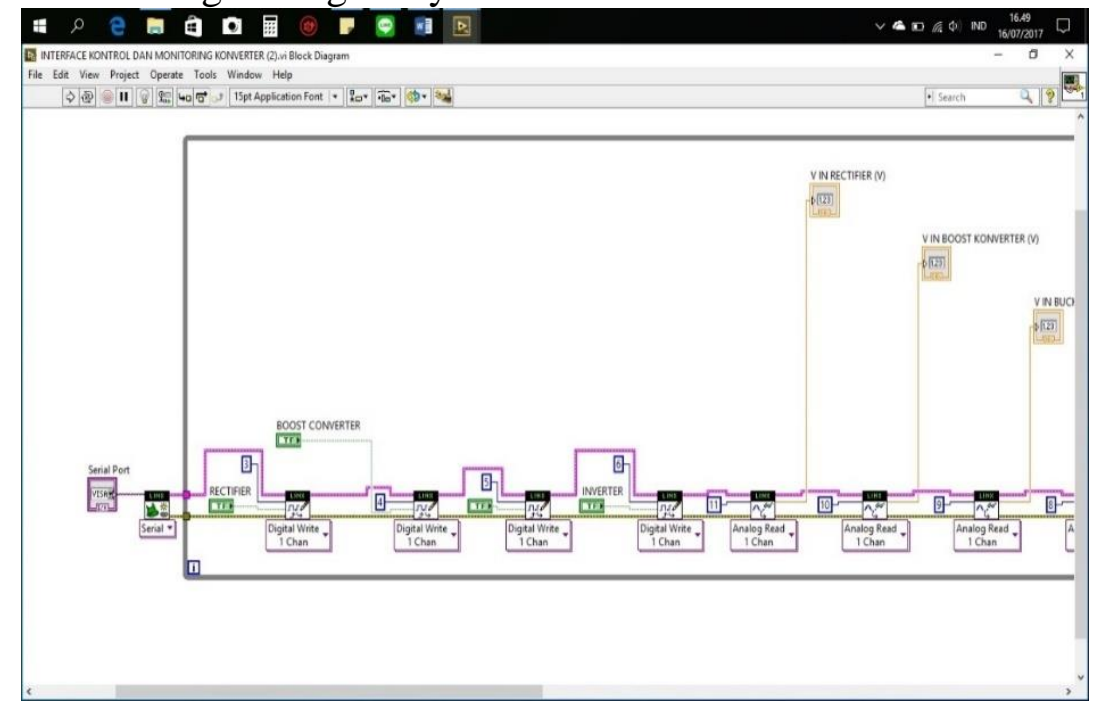

Gambar 10. Blok Diagram Labview

\section{c. Membuat Tampilan Program pada Front Panel}

Front panel adalah tampilan program. Objek- objek pada jendela ini akan terlihat oleh pengguna saat program dujalankan. Objek-objek pada front panel ini, akan secara otomatis memiliki representasi ikonya di block diagram, khususnya untuk objek-objek yang membawa data, baik data yang masuk dari pengguna ke program, maupun data yang keluar dari program ke pengguna. 


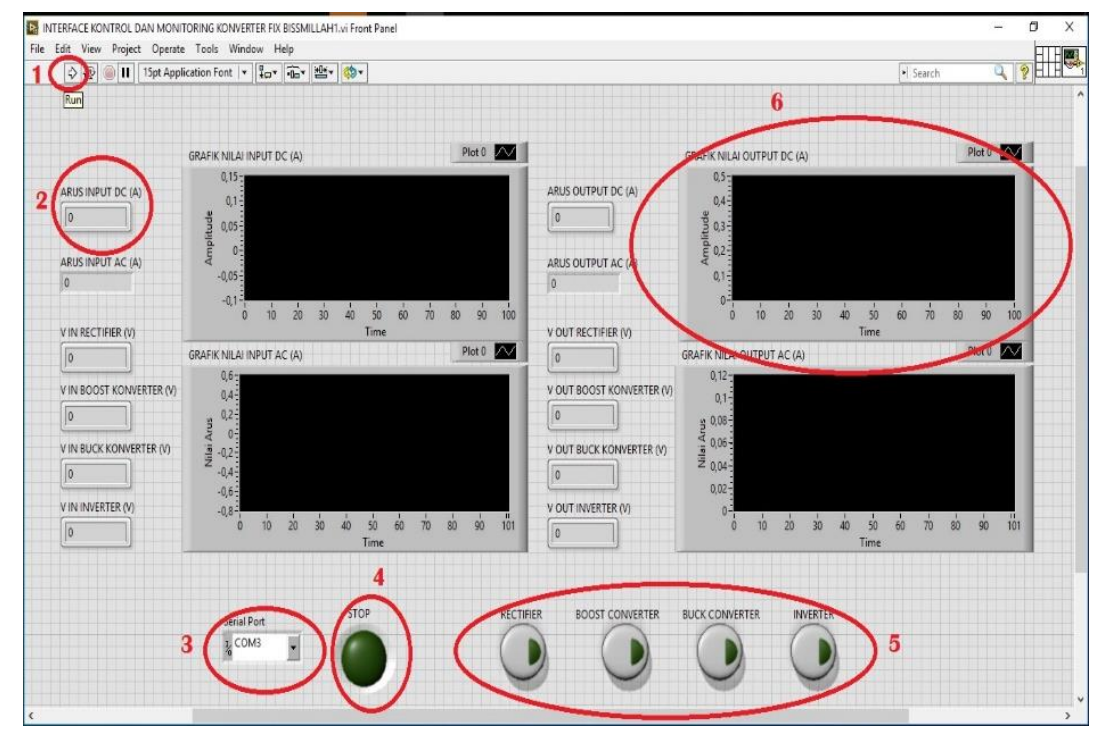

Gambar 11. Front Panel Labview

Fitur-fitur pada tampilan front panel diatas meliputi :

1. Run : untuk menjalankan program yang telah dibuat pada blok diagram.

2. Indicator : untuk memunculkan hasil pembacaan arus maupun tegangan yang di baca sensor.

3. Serial port : untuk memasukkan COM yang sesuai dengan arduino agar dapat dikomunikasikan antara labview dengan arduino.

4. Stop : untuk menghentikan program yang sedang berjalan.

5. Button : untuk mengontrol konverter mana yang akan di on/off kan.

6. Waveform Chart : menampilkan bentuk grafik arus dari rangkaian konverter.

\section{HASIL PENELITIAN}

\section{Perangkat Lunak dan Aplikasi}

\section{Program Perangkat Lunak Arduino dan Labview}

Program perangkat lunak yaitu arduino dengan labview. Program Labview digunakan oleh penulis untuk menampilkan kontrol dan monitoring arus dan tegangan dari konverter. Sedangkan arduino digunakan untuk memproses inputandari labview, sensor arus dan sensor tegangan untuk ditampilkan nilainya ke interface utama.

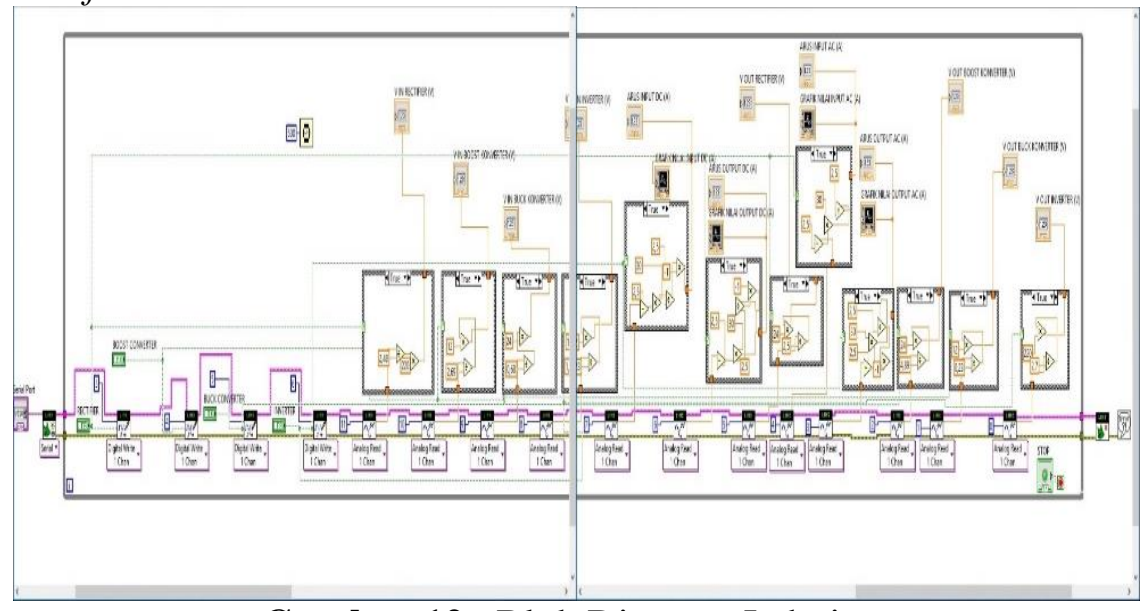

Gambar 12. Blok Diagram Labview 
Blok diagram adalah tempat pada labview yang digunakan oleh penulis mengkalibrasi sensor arus maupun tegangan dan kontrol untuk mengaktifkan konverter daya.

\section{Interface Labview}

Interface atau front panel pada labview adalah tampilan utama yang akan terlihat oleh pengguna saat program dijalankan. Front panel adalah representasi dari ikonnya pada blok diagram.

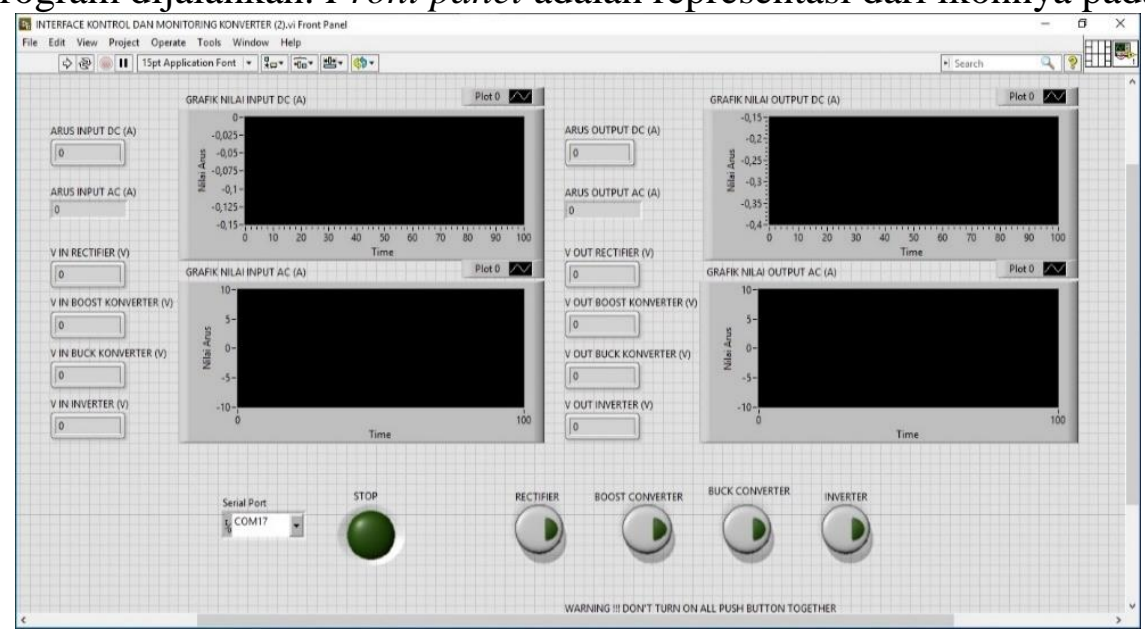

Gambar 13. Interface Utama

\section{Sistem Alat Keseluruhan \\ Sistem Alat Pada Rectifier}

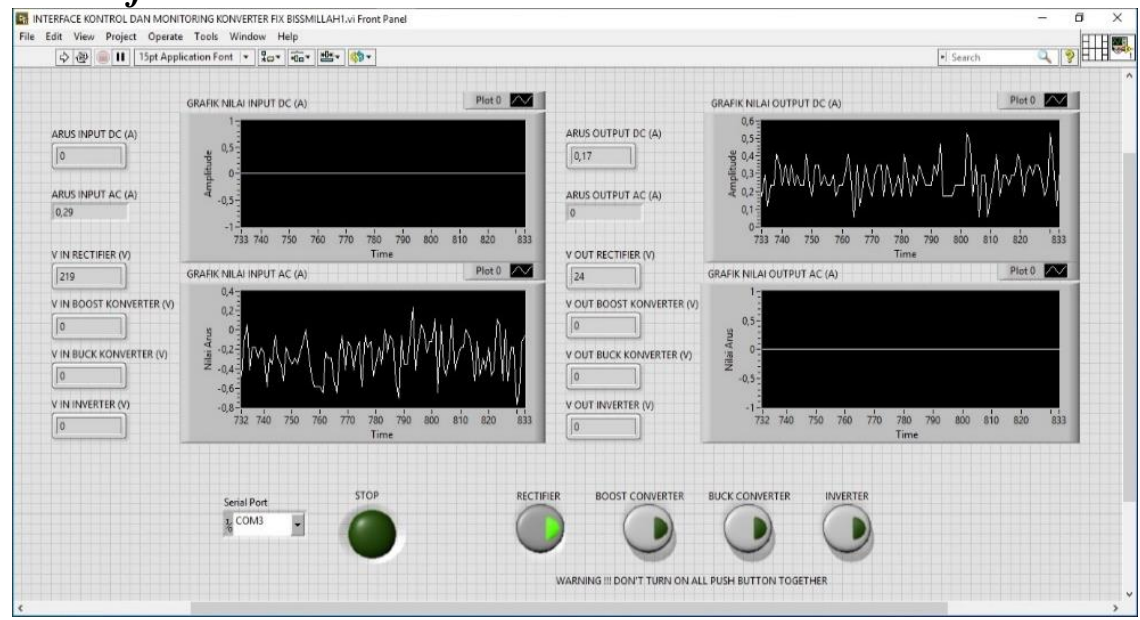

Gambar 14. Pengujian Rectifier

Hasil pengujian tegangan input, tegangan output, arus input dan arus output rectifier menunjukkan hasil yang sesuai tabel pengujian. Namun terlihat grafik dari arus input dan arus output rectifier tidak stabil karena hasil pembacaan sensor arus ACS712 yang kurang stabil yaitu pada arus input berkisar antara 0-0,32 A sedangkan arus output berkisar antara 0-0,20 A. Untuk nilai tegangan input ditunjukkan pada kotak indikator $V$ In Rectifier $(V)$, tegangan output rectifier ditunjukkan pada kotak indikator $V$ Out Rectifier $(V)$, sedangkan untuk arus input rectifier ditunjukkan pada kotak indikator Arus Input Ac (A) serta grafiknya ditunjukkan pada Waveform Chart Grafik Nilai InputAc (A), dan untuk arus output ditunjukkan pada kotak indikator Arus Output Dc (A) serta grafiknya ditunjukkan pada Waveform Chart Grafik Nilai OutputDc (A). 


\section{Sistem Alat Pada Boost Konverter}

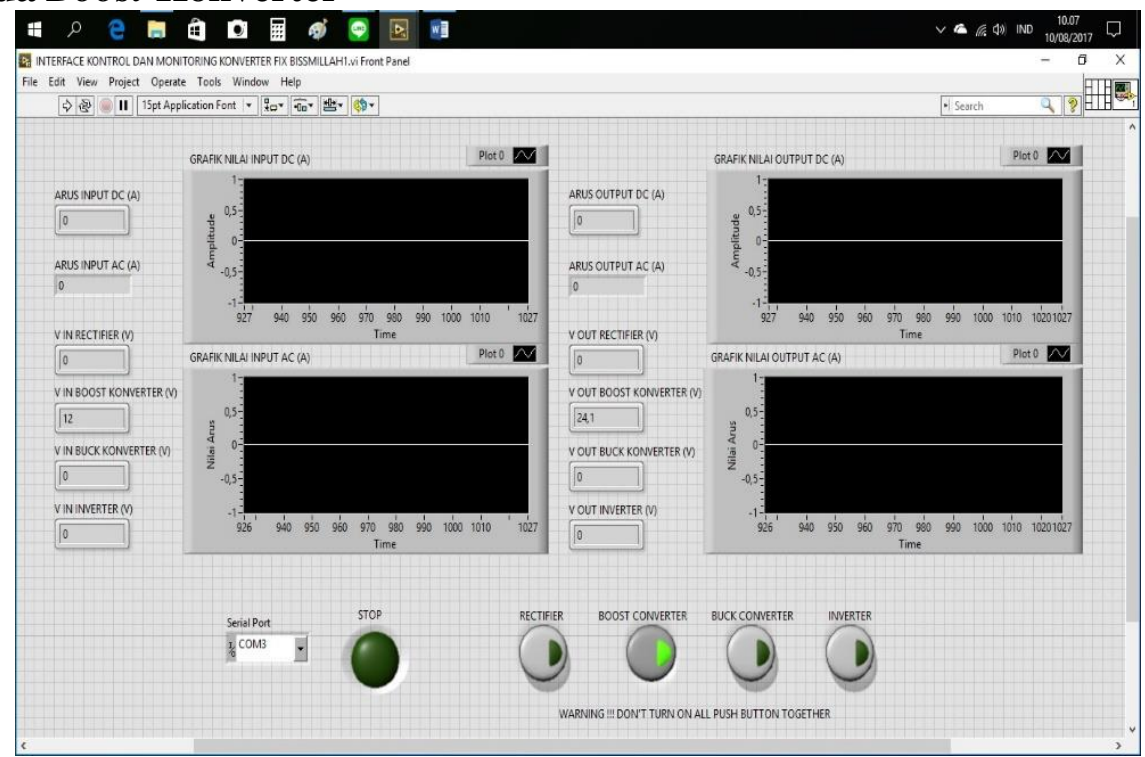

Gambar 15. Pengujian Boost Konverter

Analisa dari pengujian Boost Konverter menunjukkan tegangan yang stabil yaitu pada tegangan input $12 \mathrm{~V} d c$ dan pada tegangan output $24,1 \mathrm{~V} d c$. Hal ini disebabkan karena sifat dari tegangan $d c$ yang stabil. Berbeda dengan tegangan $a c$ yang tidak stabil.Untuk pembacaan nilai tegangan input dari boost konverter ditunjukkan pada kotak indikator V In Boost Konverter sedangkan nilai output dari boost konverter dapat kita lihat pada kotak indikator V Out Boost Konverter. Pembacaan grafik dari boost konverter tidak ditunjukkan karena tidak di monitoring.

\section{Sistem Alat Pada Buck Konverter}

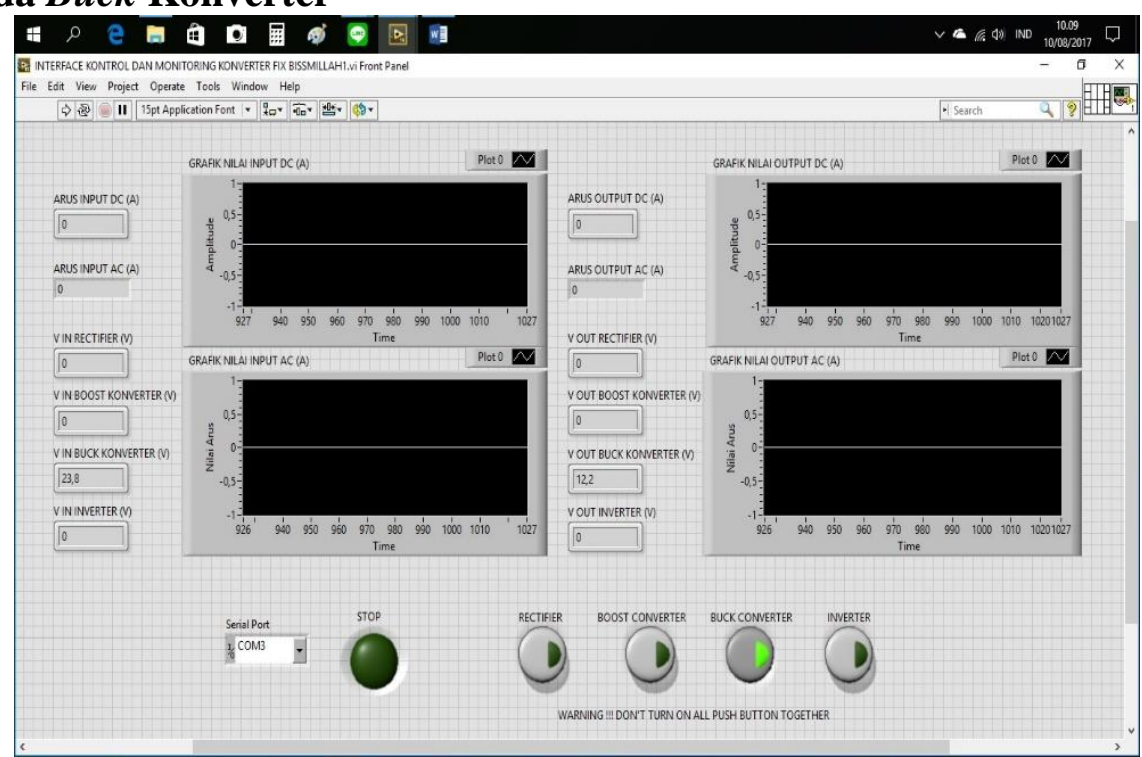

Gambar 16. Pengujian Buck Konverter

Hasil dari pengujian rangkaian buck konverter sama dengan boost konverter memiliki nilai tegangan stabil yaitu pada input $23,8 \mathrm{~V} d c$ sedangkan pada output $12,2 \mathrm{~V} d c$. Untuk pembacaan nilai input dari buck konverter dapat dilihat dari kotak indikator $V$ In Buck Konverter dan untuk tegangan output dapat dilihat dari kotak indikator $V$ Out Buck Konverter. Pembacaan grafik dari buck konverter tidak ditunjukkan karena tidak di monitoring. 


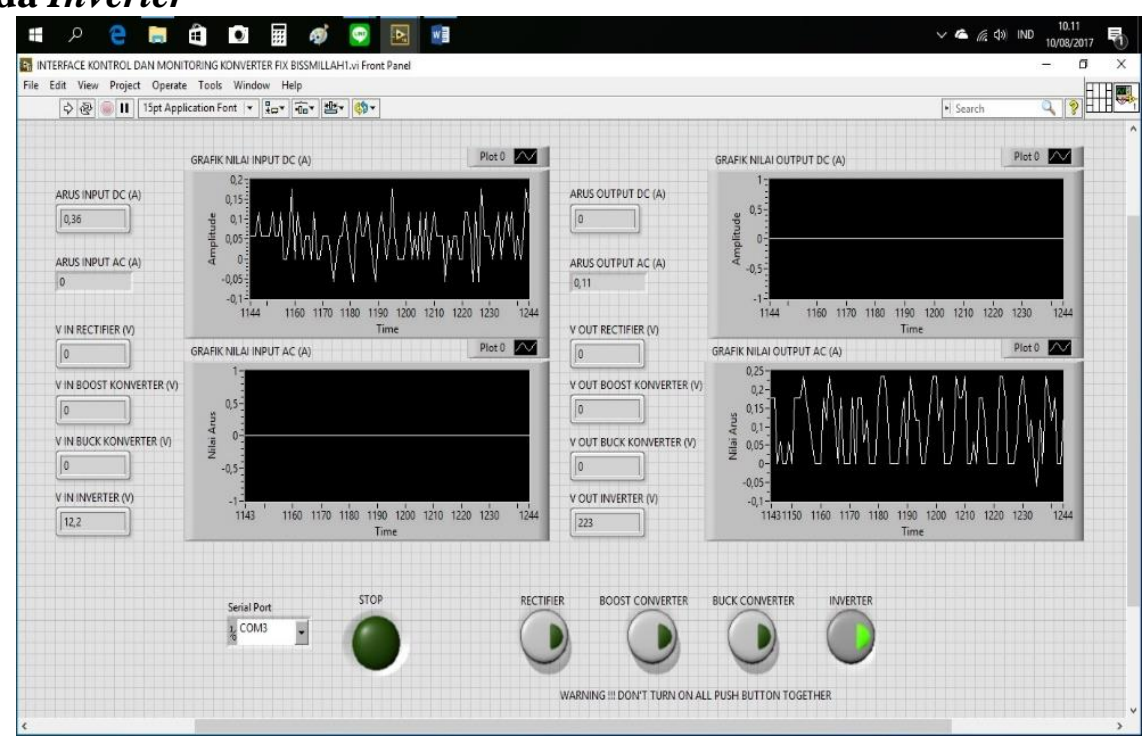

Gambar 17. Hasil Pengujian Inverter

\section{KESIMPULAN}

Dari semua uraian, pembuatan, pengujian dan analisa tentang "Rancang Bangun Trainer Konverter Berbasis Arduino Mega 2560 Sebagai Sarana Praktikum Di Laboratorium Listrik Politeknik Penerbangan Surabaya " maka dapat disimpulkan :

1. Perangkat keras (Hardware) pada alat yang penulis buat terdiri dari rangkaian power supply 12 $V d c$ dan $24 V d c$, rangkaian sensor tegangan =ac ZMPT101B, rangkaian pembagi tegangan untuk sensor tegangan dc, sensor arus ACS712, serta rangkaian Microcontroller Arduino Mega 2560 .

2. Perangkat lunak (software) pada alat ini berupa program pada labview berupa icon-icon yang digabungkan membentuk suatu perintah untuk mengontrol dan memonitor konverter daya yang penulis buat, kemudian dikoneksikan dengan microcontroller arduino mega 2560 sebagai alat untuk memproses perintah dari labview.

3. Dari hasil pengujian yang dibagi menjadi dua bagian yaitu rangkaian kontrol dan rangkaian monitoring, secara keseluruhan alat sudah berfungsi dengan baik namun masih ada beberapa kekurangan pada monitoringnya, kurang presisinya nilai sensor arus dan tegangan menjadi masalah bagi penulis dalam pembuatan alat ini.

4. Pada setiap sensor memiliki nilai adc (analog to digital) yaitu nilai dari hasil konversi input analaog ke digital. Hal ini dilakukan karena arduino hanya dapat menerima data digital saja.

5. Nilai toleransi naik turunya tegangan yaitu \pm 5 Volt, apabila melebihi batas toleransi tegangan dikatakan jelek untuk mensupply suatu beban.

\section{DAFTAR PUSTAKA}

Allied Electronics. Datasheet Arduino Mega 2560. Italy: Allied Electronics

Artanto, Dian. 2012. Interaksi Arduino dan LabView. Jakarta :Elex Media Komputindo

Jatmiko W,I. 2010. Elektronika Daya. Yogyakarta : Kemenrian Pendidikan Nasional Universitas Negeri Yogyakarta

Rashid H,M. 2007. Power Electronics Handbook 2nd Edition. United States: Elsevier inc.

Tim Fakultas Teknik Univesitas Negeri Yogyakarta. 2003. Teknik Dasar Rectifier dan Inverter. Jurnal

Yogyakarta :Dirjen. Pendidikan Dasar dan Menengah Depatemen Pendidikan Nasional

Andrianto.D. 2008. Analisa Kestabilan DC-DC Konverter Dengan Metode 
Penambahan LC Disisi kontrol. Skripsi. Jurusan Teknik Elektro. Semarang: Fakultas

Teknis. Universitas Katolik Soegipranata

Hauke, Brigitte. 2017. Basic Calculation of a Boost Converter's Power Stage. Jurnal. Texas: Texas Instrument Incorporated

Ibrohim, M, Bambang L.W, Ali Musyafa'.2008. Rancang Bangun Buck KonverterBerbasis Pengendali Fuzzy Pada Prototype Turbin Angin. Jurnal. Jurusan Teknik Fisika. Surabaya : FakultasTeknologi Industri. Institut Teknologi sepuluh November

MR, Fadhli. 2010. Rancang Bangun Inverter 12Vdc ke 220Vac Dengan Frekuensi 50Hz dan Gelombang Keluaran Sinusiodal. Skripsi.Teknik Elektro. Depok: Fakultas Teknik Universitas Indonesia.

Padillah, Fitra. Syahrial. Siti Saodah . 2014. Perancangan dan Realisasi Konverter DC-DC Tipe Boost BerbasisMikrokontroler ATMEGA 8535. Bandung: Jurnal Reka Elkomika. Vol.2, No.1

Tohir, NI. 2016. Rancang Bangun Catu Daya Digital Menggunakan Buck Konverter berbasis Mikrokontroler Arduino. Skripsi. Bandar Lampung: Fakultas Teknik Universitas Negeri Lampung 